\title{
Mentoring: Who And How
}

Joan H. Coll, (E-mail: colljoan@ @ shu.edu), Seton Hall University Pravina Raghavan, (E-mail: pravina9@hotmail.com), Seton Hall University

\begin{abstract}
This paper examines the concept of mentoring, defined here as a process where one individual, the mentor, passes on knowledge, experience and advice to another individual, the mentee, in trust and confidence. This process is initiated by a corporation whose purpose it is to recruit, retain and grow talented people in their organization. A survey of the history of the process is reviewed. The benefits and issues of acquiring a mentor and advancing are also covered. Four interviews are reported, the authors feel that this overview of mentoring has many applications and need not be confined to the business community.
\end{abstract}

\section{Introduction}

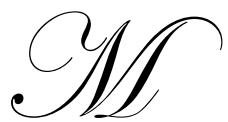

entoring is about the relationship between two (or sometimes several) people. The aim of this paper is to provide a guide on how to obtain a mentoring relationship and the potential roadblocks that exist and potential solutions to overcome these roadblocks so that there will be a successful relationship. Chemistry, an essential element to a successful relationship, is based on each individual and their styles.

A brief history of mentoring, the types of mentoring available, the top characteristics of a mentor, mentees and organizations, the benefits and finally the top issues/concerns that hinder a successful mentoring relationship are discussed. Additionally potential solutions to stumbling blocks are provided. This paper was developed based on interviews with people involved in three corporate mentoring programs and one educational program. A review of the current literature and articles dealing with mentoring supports the materials uncovered in the interviews. Interviews and surveys were conducted with mentors, mentees and program coordinators. Copies of the mentoring surveys used are in Appendix A. The main focus is on formal mentoring relationships established in corporations and how to make these programs more successful.

The top ten issues/concerns discussed are:

1. Making Time as a Mentor

2. Fostering a Process as a Mentor

3. Perceived Recognition or lack there of for Mentor

4. Being a Proactive Mentee

5. Not Becoming a Second Fiddle or Coattail

6. Receiving Bad Advice from a Mentor

7. Commitment by the Organization

8. Dedicated Program Coordinator

9. Patience

10. Feedback

\section{History of Mentoring}

Definitions: According to some researchers, mentoring has been around since the creation of time. It is a process where one individual, the mentor, passes on knowledge, experience, advice and council to another individual, the 
mentee. It seems like a straightforward definition. However, it is not. Mentors have been described as "someone who helps us learn the ways of the world, someone who has our best interests at heart" or "mentoring in the workplace focuses on professional growth and learning, although some mentors facilitate their mentees' personal or emotional development as well" (Abbott, 2000) or a more formal definition such as, "facilitated mentoring is a structure and series of processes designed to create effective mentoring relationships; guide the desired behavior change of those involved; and evaluation the results for the protégés, the mentors, and the organization. (Murray, 2001)

The word mentor is derived from Greek mythology, The Odyssey, written by Homer. The story relates that when Odysseus went off to the Trojan War, he left his friend, Mentor, to take care of his son, Telemachus. Odysseus was away for more than twenty years and the word took on the definition of a wise and trusted teacher or counselor and has been used ever since.

One can conclude that the basis of mentoring is trust, wisdom and counseling. However, research and use of mentoring as a process started in the mid 1970's. This usage coincided with the entry of more women into the workforce and was utilized as an individual educational process. Mentoring as a process was popularized in the 1980 's. In the 1990's mentoring was institutionalized and many corporate programs were established to help recruit, retain and grow talented individuals. One of the most famous mentoring programs is GE's Financial Management Program, started in the 1990's to recruit and grow talented financial professionals to develop the next generation of leaders for the company. Mentoring is used by corporations, educational institutions, non-profit organization, service organizations and various other intuitions. To date there is no standard definition or processes among mentoring programs. Mentoring is defined, however a person or corporation wants but usually encompasses trust, wisdom and counseling.

We define mentoring process as one in which individual, the mentor, passes on knowledge, experience and advice to another individual, the mentee, in trust and confidence. This process is initiated by a corporation whose purpose is to recruit, retain and grown talented people in their organization.

\section{Mentoring}

Classifications

Mentoring can be classified in terms off formal vs. informal; short-term vs. Long-term; primary; secondary; and group mentoring

Formal mentoring is developed to facilitate the meetings of mentors and mentees. Formal mentoring relationships are structured by an organization with a particular purpose or objective. On the other hand, informal mentoring is not facilitated by an organization and has no organizational involvement. This does not mean that the mentoring sessions are without purpose or structure.

Either type of mentoring, informal or formal can be long-term or short-term in nature. Long-term mentoring (Basile, 1998) exists when a mentor commits for life or for the long haul. This mentor is used by the mentee regularly and is an integral part of the mentee's support network for growth, development and obtainment of goals. The short-term mentor is used in the same capacity as a long-term mentor but does not stay with the mentee for a long period time. Most mentor relationships are started with the idea that they will be short-term and, depending on chemistry and commitment, turn into long-term relationships. Clutterbuck and Meggins on (1999) describe a long-term mentoring relationship as any relationship lasting for over three years.

A primary mentor is an individual who the mentee designates as the most important person for advice and council. The primary mentor usually deals with more aspects than professional growth objectives. The primary mentor may change as the mentee develops and grows. The best way to think of a primary mentor is the person who the mentee most values advice from and with whom s/he can discuss a variety of subjects. 
A secondary mentor (Jipson, 2000) is an individual who advises the mentee in a particular area. For example, a mentee may have a primary mentor with whom s/he talks about life, politics, business acumen and additionally have a secondary mentor with whom s/he talks only about the stock market. The secondary mentor is just as important as a primary mentor and most mentees have one primary mentor and several secondary mentors.

The final classification of a mentoring is group mentoring. Most people think of mentoring as a one-on-one process but this does not have to be the case. Group mentoring (Dansky, 1996) has become more popular because it allows for many people to have access to mentors, cuts down on the cost of mentoring programs and also allows mentees to receive several viewpoints. Group mentoring takes on a variety of forms. The main tenet of group mentoring is that the group is one unit and listens and gives advice on issues together. Group mentoring is usually structured as a limited group of people who have gathered for a specific purpose. An example of group mentoring is 5 freshmen scholarship communication students being mentored by a panel of professors. These students mix and talk with the same panel throughout their collegiate careers. New students cannot join the group and the primary dynamics of groups do not change.

Mentoring: sponsors, coaches, role models and momentary influencers (Borick, 1998, Minter \& Thomas, 1998)) are concepts sometimes confused with mentoring. A sponsor is a person who acts as an advocate for one or more people in the organization or supports a particular initiative. This person donates his/her time and money to the cause but does not advise or council anyone. Sponsors tend not to develop one-on-one relationships with the sponsorees.

A coach imparts technical knowledge or teaches someone a process or system. The focus is to "coach" or help someone through a particular task but that is where the commitment ends. Once the task is accomplished, s/he moves to coach someone new. A role model is one whom someone wants to emulate. This can be known or unknown to the admirer. There is usually no formal relationship between role models and their admirers.

A momentary influencer is someone who comes into a person's life for a brief time and gives the mentee some advice or wisdom. These people influence the way the mentee thinks or approaches life or an issue. When compared with the definition of mentoring it is clear that none of these roles qualifies as mentoring.

However, the common thread among the various types of mentoring relationships is the chemistry of the people involved. Mentoring for both the mentors and mentees is about commitment to each other. If there is no commitment to the process or each other, the relationship will fail. As with any other personal relationship, there are some basic elements needed from the mentor, mentee and the organization to allow the process to work. These elements are commitment, trust and effective communication. A lack of these basic elements will cause the relationship to fail or be less productive. In addition to these three basic elements, there are key traits that make for more successful mentoring relationships and these help create the right relationship dynamics.

\section{Mentor Characteristics}

Shea (1992) suggests that individuals with the following characteristics or values tend to excel in the role of mentor: strong interpersonal skills, good listening skills, credibility, competence, supportive non-controlling participation, empathy, a patient approach to and a risk taking attitude and experience.

Strong interpersonal skills are critical in creating and maintaining a positive and successful mentoring relationship. The mentor is the guide and advisor and needs to communicate well with the mentee. Therefore, it is critical that the mentor can properly articulate his wisdom, advice or council. Failure is the result when communication is ineffective

Possessing good listening skills is important for both the mentor and mentee and it is sometimes overlooked on the part of the mentor as they are seen as the advice givers. However, for a good mentor to advise or council a mentee, s/he needs to understand and listen to what the mentee is saying. What is the mentee looking for? What is the mentee asking about? How can s/he help them? Good listening skills are critical for any relationship. 
Credibility is important in establishing a mentoring relationship and fosters trust. A mentor must be known as someone with high moral and ethical standards and is willing to help others. If the mentor is not seen in a favorable light by the mentee or organization, it can cause distrust with the mentee and may be detrimental to mentee's career.

The mentor has to be either highly respected or have exemplary technical skills or status or prestige or possess some skill set that the mentee regards as valuable. If the mentor can bring no experience or knowledge to the table, then s/he cannot help or guide the mentee.

Most successful mentors express high expectations for the mentees and encourage their mentees to achieve the established goals. The mentor needs to build the mentee's confidence as well as his/her skill set. Successful mentors are able to visualize what the mentee can become and do not only focus on the "here and now." However, the mentor needs to realize that $\mathrm{s} / \mathrm{he}$ can assist, advise and council a mentee on how to grow and achieve the mentee's goals but cannot assume responsibility for that growth. If a mentee does not want to grow, no amount of encouragement from the mentor will cause the mentee to grow. The mentor is not responsible for the mentee as s/he is not a parent but rather functions as a support to the mentee.

Empathy is the ability to understand what someone is going through and still allow that person to see that growth and development are possible and likely. A mentor must have emotional intelligence' and foster this sense of intelligence in the mentee. This skill of emotional intelligence helps the mentee grow. Emotional intelligence is defined by Goleman (1995) as involving five key skills: knowing one's emotions (developing self-awareness), managing emotions (handling feelings), motivating oneself (marshalling emotions in the service of a goal), recognizing emotions in others (developing empathy), and handling relationships (increasing social competence). A mentor has to be able to understand what the mentee is feeling but not let these feelings derail the progress or commitment to obtaining a goal.

Patience and risk taking are skills needed for any relationship. The mentor has to be patient with the mentee as the mentee is learning and assimilating what the mentor has said or done. The mentor is the wise old owl and has "been there and done that", whereas, the mentee is getting there and may not do it as quickly as the mentor hopes for. Also, risk taking is important. The mentor is taking a risk by giving of him/herself and sharing his/her personal thoughts and experiences. The mentor takes risk by giving and receiving feedback on performance of both parties.

Most successful mentors were previously mentees and have had very successful relationships with their own mentors, allowing them inherent understanding of the benefits of mentoring and allowing them to give back what they received. This does not mean that people who have never had a mentor are not suitable for the task but rather that people who already have a mentoring relationship are more willing to be a mentor and also understand what is involved

\section{Mentee Characteristics}

Being proactive, respecting the mentor's time expenditure, acting on information provided, taking responsibility and demonstrating a willingness to learn and grow, respecting the mentor's efforts and rising to the challenge to gracefully accept criticism and feedback are cited by Shea (1992) as desirable characteristics of successful candidates for mentoring.

A mentee needs to be proactive in selecting and searching for a mentor. Even in a facilitated process, the mentee needs to be able to determine and search for his/her mentor. If a mentee is not proactive then this probably shows a lack of commitment or drive in the mentee. Showing that a person cares about his/her development and searches for assistance is a good sign that the person is open and willing to be mentored.

The mentor is usually a very busy individual and is making a commitment to the mentee placing a strain on the mentor's time and therefore should be respected. This does not mean that the mentee's time is not important but 
the mentee must realize that the mentor is using valuable company or personal time by assisting the mentee's development and growth.

When a mentor gives an assignment, the mentee shows commitment and respect by taking action on it. In terms of advice, the mentee should be willing to listen and take a decision, though not blindly. If the mentee does not agree with the suggestion, the mentee should discuss his/her feelings with the mentor. Usually, the mentor does not give assignments or advice on the premise that the mentor will benefit. The mentor gives this information to the mentee to assist the mentee. When a suggestion is not followed it shows a lack of commitment by the mentee to the mentor and signals a break-down of the rapport built between the two.

The mentee needs to realize and accept that he/she is putting him/herself in a situation of seeking advice and council on how to develop. The mentee must assume the responsibility of listening and taking action and cannot pass this responsibility to the mentor. The mentor does not assume the role of the mentee's parent. The mentor is someone who is willing to help or advise the mentee but is not responsible for the mentee. Only the mentee can be responsible for his/her development and growth.

The mentee needs to acknowledge and respect the mentor's efforts. If a mentor makes an introduction or sets-up a meeting for a mentee, the mentee should strive to make the best impression or there is a risk of rupturing the relationship. If a mentee is uncomfortable with a course of action taken by the mentor the mentee should be proactive and arrange to resolve the issue.

This relationship focuses on the development and growth of the mentee. Although difficult, the mentee has to be willing to openly accept criticism and feedback, demonstrating strength and the willingness to grow. Therefore, the mentee needs to be able to accept and learn from the advice and observations.

\section{Organization Characteristics}

Abbott (2002) delineates the traits that are necessary for the organization in a facilitated mentoring program: leadership commitment, clearly articulated program objectives, set program parameters, voluntary participation, length of the mentoring assignment, time commitment, scope of the mentor-mentee relationship, budget, procedure and criteria for matching mentors and mentees, appointing a program coordinator, training all involved, providing ongoing support and program monitoring, evaluating the process, putting guidelines in writing, and providing incentives.

If the program does not have commitment from top management, it will fail. As with other corporate initiatives mentoring needs to become part of the culture and processes of the organization. This can only be done when the program has a sponsor or champion and is embraced by top management (McShulskis, 1997) as critical to the culture and growth of the company.

Mentors must be voluntary for the program to work. Not everyone is suited to be a mentor or wants to be a mentor and an individual who is forced to participate may lack commitment and not be able to assist the mentee. This lack will frustrate the mentee and will sour the mentee's perception of the company and process, defeating the main objective of having a mentor program. There is no conclusive evidence stating whether mentees should be voluntary. Most facilitated programs target highly talented individuals who the company feels will benefit from having a trusted advisor.

Having a dedicated program coordinator is also key to the success of the program. This person's responsibility is to run the day-today program and facilitate issues, concerns, politics and manage the environment. Having a part-time or no coordinator shows a lack of commitment by the company and does not allow for a smooth process and increases the probability of failure. The program coordinator does not have to be a senior person but should have access to the corporate sponsor or champion of the program. Additionally, the selected leader should be someone who knows the politics and culture of the company and has strong project management skills. 
Mentor training is important. Introducing mentors to guides, books or lectures on mentoring allows the mentors to find and utilize new and innovative techniques on how to mentor their mentees. As well, mentees need training in understanding what is expected of them and how to proceed in meetings with mentors. In a majority of cases, this will be the first time the mentee has been exposed to mentoring. The mentoring process is focused around the mentees - What are their goals, weaknesses, strengths, backgrounds, etc.? Mentees must have this information available when meeting with their mentors. Mentors also need a clear understanding of what the mentee wants to achieve so that the relationship can be successful.

With any process, evaluation and feedback are critical for improvement and growth of the program. A lack here leaves problems or issues unresolved. Evaluating the program is not enough; all participants need to be evaluated as well. How can a mentor improve his/her listening skills if s/he does not know it is a problem? How can coordinators deal with time constraints on certain mentors if they are not told there is a problem? Three hundred and sixty degree feedback is key to improving the program and the participants

\section{Benefits of Mentoring}

There are many benefits of mentoring to the mentors, mentees and organizations. Every book and article (for example Basile, 1998, Dansky, 1996, Hill \& Bahnuik, 1998) articulates the numerous benefits of these programs. The main focus is not on the benefits but solutions to certain issues, therefore the following are just some benefits. One can list the benefits to the mentor (Basile, 1998, Goodale, 2001)) as:

$\begin{array}{ll}\text { 1. } & \text { Better Sense of Self } \\ \text { 2. } & \text { Increases Productivity } \\ \text { 3. } & \text { Encourages Creativity } \\ \text { 4. } & \text { Enhances Reputation } \\ \text { 5. } & \text { Leaves a Legacy }\end{array}$

There are numerous reasons why mentoring benefits people and organizations. For mentors, the above list only encompasses a few of the benefits. By becoming a mentor, an individual searches within him/herself to recognize his/her strengths and weaknesses. By doing this search, s/he finds ways, to improve on weaknesses and to utilize assets. By becoming a mentor, interpersonal skills are enhanced and these improvements flow into the mentor's regular work and thereby increasing the mentor's productivity. By teaching and planning for the mentee session, mentors think more about actions taken and may see areas of improvement within the firm or identify weaknesses within a process causing beneficial change to the firm. The greatest benefit for most mentors is leaving a legacy by having successful prot6ges.

\section{Benefits to the Mentee}

Although not all-encompassing the list below highlights some of the more recognized benefits of being a mentee.

1. Increases Productivity and Success

2. Provides Coaching and Advice on Goal Setting

3. Improves Career Satisfaction

4. Provides rapid Assimilation into the Corporate Culture

5. Accelerates Leadership Development

The greatest benefit to the mentee is having someone who can assist the mentee in developing and growing within the organization. Mentors help their mentees adapt to a new environment quicker as they can offer advice on how to handle certain people or how to obtain certain results. Research shows (Young \& Perrewe, 1997) that employees with good mentoring relationships tend to stay longer and are more loyal to a firm. They feel that they have gained something that might not be available in other firms and also they have a support network for tough times. 


\section{Benefits obtained by the Organization}

Bell (2000), Messmer (1998) and Higgins (2001) provide a list of benefits that accrue to the firm if mentoring is a successful component of the corporate culture.

1. Increased Productivity

2. Improved Cost Effectiveness

3. Improved Recruitment Efforts

4. Higher Retention of Intellectual Capital

5. Efficient Translation of Knowledge into Practice

Organizations benefits by having a more productive work force (both the mentors and mentees), increased job satisfaction from most participants, improved recruiting efforts due to a successful program. One area not highlighted but seen is cost effectiveness. By having mentors work with mentees, on the job training is provided at relatively low cost. Also, many programs utilize the mentor sessions for the initiation of projects that benefit the firm.

Another major benefit is the efficient transfer of knowledge into practice. Mentees in successful mentor relationship are able to "hit the ground running" faster than employees without the benefit of a mentor. Mentees became revenue producers quicker because someone assisted them in understanding the organization and processes better. The transfer of knowledge to practical experience takes time which is shortened when a mentor can advise and council a mentee.

\section{Top 10 Issues/Concerns and Potential Solutions}

Subject interviews produced 10 issues or concerns identified by participants in a facilitated mentoring process. For each issue, there are potential solutions that can be implemented by the organization or coordinator. The solutions are based on research from reading, interviews and personal reflection. These are not panaceas but suggestions that may spur more thoughts.

As with any process there are bound to be numerous issues or pitfalls. Good communication among all involved parties will help find a solution. The characteristics described above are key to achieving success in a mentoring program. Also, if there is no commitment, trust and effective communication among the mentors, mentees and organization, then a successful mentoring program will be unlikely.

\section{Top Concerns or Issues for Mentors}

\section{Scheduling or Devoting Time to a Mentee or the Process}

Mentors are very busy people. How does one go about scheduling time in an already crammed calendar? This is a question or concern from most mentors about becoming a mentor. Also, mentees list this as a top complaint, "my mentor does not make time for me or can not seem to find the time to answer my questions. As with anything else, first, the mentor must question his/her commitment. The mentor's commitment is critical to answering if $\mathrm{s} / \mathrm{he}$ is willing to find the time to spend with the mentee. Assuming that $\mathrm{s} / \mathrm{he}$ is committed to the process then the following can help in finding time for a mentee.

\section{Communicate with the mentee about the mentor's expectations on his/her time}

Does the mentee want to meet with you for weekly chat or does s/he prefer to come to you when s/he reaches an impasse? The amount of time a mentor spends with the mentee will depend on the expectations of both the mentor and mentee. There has to be a meeting of the minds on what the goals, objectives and timescales of the relationship are. If these are effectively communicated then both parties can schedule time and expectations accordingly. 
3. Schedule a meeting around breakfast or lunch. This allows the mentor to do two things at once.

It is also a predefined time that can be put into your schedule and allows the mentor some time to reflect with the mentee.

\section{Have the mentee shadow the mentor or attend a teaming development activity.}

Mentoring is not about conversation flow. It is about imparting knowledge to the mentee. If the mentee is interested in becoming a better public speaker, invite the mentee to an event where the mentor will be speaking. S/he can shadow the mentor and learn from example what to do. By including the mentee in a project, $\mathrm{s} / \mathrm{he}$ is able to learn from observation rather than from a speech

\section{Take a mentee to an event.}

There are many events that mangers and executives attend. Taking the mentee along to network with others as well as learn from observation will allow for the mentee to see his/her mentor in action but also allow him/her to expand his/her wings. The mentee also gains access to another level within the corporation.

\section{Assign meaningful work or task to the mentee.}

This frees some time for the mentor and allows the mentee to work on project that is different. Also, it allows both parties to work towards a mutual goal. The mentor must remember that the project should be something that is inline with mentee's objectives and not to over-utilize the mentee as a workhorse.

\section{What Do I Do as a Mentor?}

1. Mentors are supposed to be skilled at their task. However, mentors are human and do not know how to handle all situations. To be an effective mentor, a mentor must have developed a strategy for conducting a mentee session.

2. First, discuss, what the expectations of the mentee are for each session or group of sessions similar to what was done be flexible. The coordinator should have a candid discussion with the potential mentor and determine if the potential mentor is willing to participate in the program.

3. The mentee should have his/her goals, objectives, expectations, strengths and weaknesses outlined before meeting with the mentor. No one knows a mentee better than the mentee. Coming to a mentor session unprepared shows a lack of commitment to the process. A mentor is there to guide not to kick-start a mentee's career.

\section{Mentees Concerns or Issues}

1. Mentee's must be proactive in contacting and building the relationship with the mentor. The mentee may, at times, need to initiate contact with the mentor. The mentor will not always know when the mentee needs help. If the mentee is stuck, then the mentee needs to pick up the phone or make appointment to see discuss the issue.

2. Giving feedback on advice or suggestions given by the mentor is key for the mentee's development as well as the mentor's development. The mentee should feel comfortable enough to comment on how something worked or why it did not work. This allows both the mentor and mentee to grow but also shows the mentor that the mentee is listening while not becoming dependent.

3. If a mentee creates a solution for improvement of a process or activity, s/he should talk with the mentor. If a mentee can make positive changes within the organization, it furthers the program, benefits the mentor and improves the status of the mentee. Mentees should be careful and not try to change processes or ideas overnight as they may be part of the culture or an integral part of the firm. Here, the role of the mentor is crucial - provide guidance.

4. How not to become a coattail or second fiddle 
5. As mentoring is about the relationship between the mentor and mentee, there is a tendency to become dependent or to merge with the mentor's growth and development. It is not bad to have someone in the higher echelons thinking well of the mentee and pushing for his/her success. However, if a mentor is bad or makes a wrong move, this can reflect on the mentee. The mentee does not want to pin her career to one person. In today's corporate environment, coat tailing with one person can be political and career suicide for the mentee.

6. The mentee must realize that the mentor is a guide not the one responsible for the mentee. The mentor can open doors and introduce the mentee to the right situations. The mentee needs to be proactive in searching for secondary mentors and other opportunities. By having several mentors and networks, a mentee can avoid the pitfall of being associated with and dependent on only one person for career progression.

7. Mentee should seek out assignments or activities that expose him/her to many people in the organization and also allow the mentee to be seen as an independent person in the organization. A mentee can use the mentor as a sounding board or idea generator for finding ways to approach problems and work with other people.

8. If the mentor is incompetent, uncommitted, disinterested, malicious or is very negative, the mentee should first try to work the problem out with the mentor. But if things are very bad, the mentee should approach the coordinator and ask for a change of mentor. A mentee is responsible for his/her individual development and if the mentee is lacking the right tools, the s/he needs to search and find the right tool. Not every relationship is going to work, therefore, the mentee needs to leave the relationship in a professional manner. Do not to bum bridges when leaving a relationship

9. Receiving Bad, Advice. Mentors are fallible. A mentor is only offering advice or council based on what s/he knows about the mentee and how the mentor succeeded.

10. If the mentees hear the advice given by the mentor and does not feel comfortable with advice, the mentees should ask why they do not feel comfortable. If s/he is uncomfortable because it forces the mentee out of a comfort zone or the mentee has never done it before, then perhaps the mentor has not given bad advice. The mentor may have given the mentee some advice to provide a growth experience. Growth is sometimes painful and uncomfortable and the mentee may be confusing bad advice with growth.

11. If the mentee has reflected on the advice and realizes that this is something the mentee feels uncomfortable with because it compromise his/her value system or ethics, then perhaps it is bad advice for the mentee. The mentee should openly discuss with the mentor to why s/he is not taking the advice and explain his/her reasoning. The mentee should avoid blaming or diagnosing but should focus the discussion on the mentee's influences and thought patterns.

12. If the mentee after reflection feels that the mentor is giving bad advice on a steady basis and that s/he does not understand the mentee, then the mentee should have a discussion with the mentor about what the mentee wants to achieve and perhaps revisit established objectives and goals with the mentor. (Feldman, 1999) It is possible that this may not be the right mentor for the mentee, and if this is the case, discussing a possible change or co-mentor should be explored with the coordinator.

\section{Top 4 Concerns or Issues for the Organization}

\section{Commitment to the Program by the Firm}

Commitment by the firm is critical in making the program work and succeed (McShulskis, 1997). There are three major areas of commitment that the firms needs to push for: (1) recognition of the program and especially the mentors (as discussed in point 3), (2) training of mentors and mentees and (3) selection process of mentors and mentees.

Training is very important for all the participants. Without the right skills success will be illusive. If a firm truly commits to mentoring, they need to spend money on training. This does not necessarily mean that the cost must be exorbitant. To reduce costs the firm can meet with a mentoring consultant firm and have their program coordinated for them and perhaps sponsor or select a group of mentors to be trained professionally. The trained mentors can then train others or be a panel for advice or have office hours for other mentors. 
Another route is to avail the coordinator with books and on-line help about setting up programs, planning materials and setting goals and objectives. A firm can either purchase several books or set a standard outline or description about the process and materials. Determining a standard set of materials to be given to each mentor and mentee should be part of the coordinator's role. If a mentor has questions about process or wants more information, $\mathrm{s} / \mathrm{he}$ can look on-line and find more material or go to the panel of mentors for advice.

Mentors do not have to be trained together as most mentors can assimilate information on their own. If they have questions, they should have access to information. It is important to have at least one trained mentor who can assist the other mentors in finding alternative sources of inspiration. Also, having a mentor network (Higgins, 2001) allows mentors to swap stories and experiences with each Creating a 'mentor only' email list enables mentors to rely on each other.

Mentees, however, will need more formal training. As stated earlier, this may be the first time participants have engaged in a formal mentoring relationship. Therefore, during orientation, which most companies have for new recruits, an hour or two should be dedicated to the mentoring process. The agenda should cover topics such as how mentoring works, how to select a mentor, how to set goals and objectives, what a mentee should do and time lines (Gregg, 1999). By having a formal information sessions, the corporate culture is signaled that mentoring is as important as understanding the computer systems or the corporate objectives. There should be a separate formal session with both mentors and mentees on feedback as training material should also include giving and receiving feedback

Training for new lateral employs who are to be mentored can take place with the coordinator on one-on-one basis. It would be similar to new recruit training but may not be as long as the new lateral employee may already be a participant in a mentoring program.

The selection process (Lee, Dougherty \& Turban, 2000) is critical in setting up the mentoring program. If they force someone to mentor and do not screen, the firm is setting up the program to fail. A firm usually does not force a marketing manager to become the journal entry expert because they need journal entry experts. Were this done there would be many complications. This same principle applies to mentoring. Individuals must want to mentor.

If someone wants to be a mentor and does not have all the skills, then training becomes more critical and perhaps one-on-one training with another mentor will assist this individual in becoming a mentor. Some good mentors may be willing to mentor and will put forth the effort to learn how to be a good mentor. A selection criterion for mentors is critical.

As for selecting mentees the firm must set objectives for qualifying. Do all employees get a mentor or just a select group? The culture and strategic plan determine the policy. As with mentors, mentees must want to participate in a mentoring relationship. However, it is easier for the mentee to be convinced to participate then a mentor. Mentors need more support from the firm. Mentees get immediate benefits as the process is focused on them.

\section{Dedicated Coordinator}

A dedicated coordinator is also critical to a mentoring program. Someone needs to shepherd the program, handle conflicts, search for mentors and mentees, provide assistance and implement feedback. This is not a part-time job and if the firm is committed to having a successful program, then they need to commit resources. A dedicated coordinator does not need to be a very senior person in the organization. It needs to be someone who commands respect and is highly regarded. The person should also know how the company works and one who understands the company culture. A retired senior manager is good choice for a program coordinator.

If choosing a retiree is not an option, having a coordinator who is junior in the organization, one who runs the day-to-day process and is supported by one or two executives, one who can talk with mentors or senior staff, is 
another option. This way the senior members can spend quality time on the mentoring program but not let it be their number one priority. This is a form of job sharing.

The coordinator should either be in the HR department or have close working relations with the HR and recruiting teams. They will need to make sure the program works within the HR framework and will probably have to coordinate efforts within the HR framework.

Another option is to hire an outside consultant to initiate and run the program. The firm should ensure that someone in the firm is shadowing the consultant so that when the consultant leaves, the internal person will be ready to step into the role as program coordinator and keep the program running.

\section{Patience}

The firm needs to have patience. Setting up a mentoring program does not happen over night and results will not be seen within the first year. This has to be understood when a firm decides to make mentoring part of its culture. The firm itself may not see real results for three to five years because the culture must change to accommodate the mentoring process and for most firms change is not immediate especially when it comes to changing the culture. An additional concern is that the first career crisis (loosing employees) for most new employees occurs within the first two years. A long-term perspective is needed to evaluate the process. For example, if retention rates are higher in three years time, it may be due to mentoring. Constancy of support of the program cannot diminish even in down times. Loyalty is greater in firms using mentoring.

Even if the firm cuts back on spending, mentoring can still take place. Most of the solutions above can still be accomplished with minimal expense to the firm. However, the firm must not cut the program and then hope to start it again when times are good again. This signals a lack of commitment and people will not try a second time. Also, any benefit derived from the program will be lost to the firm. Patience and commitment to the process will allow the firm to reap the long-term benefits of the mentoring process.

\section{Feedback}

Feedback is an important aspect of the mentoring process (Schweitzer, 2001). One of the most shocking revelations in interviewing the program coordinators is that there is very minimal all around feedback in the programs. This was amazing as this is a potential roadblock to enhancing and improving the mentoring process. The mentoring process is about communication and if people cannot freely communicate about weaknesses and strengths chance for improvement or development is diminished.

Training on feedback is needed. People need to learn how to constructively give and receive feedback. This is not an easy process. There are politics involved when giving and receiving feedback. Anonymity is key when mentees give feedback to their mentors. When this is not possible, then the program coordinator needs to be the go between and suggest areas of improvement to the mentor.

If the mentor and mentee have a good relationship, feedback will flow throughout the process. However, formal feedback is needed so the coordinator can track the program and highlight its strengths. One can expect that close scrutiny is necessary. The formal feedback process allows for the collection of data to support the success of the mentoring process.

Feedback can also be used as tool in compensating mentors and setting up funds or mentor accounts. If a mentor is doing well, then s/he should be compensated. However, if a mentor is not doing well, then s/he should receive more help from the coordinator. S/he should not be penalized for being a less than stellar mentor. This will send the wrong signal to the corporate community. The mentor volunteers time and experience. 
Mentees need to learn how to accept and act on feedback. This is just one area she will be receiving feedback in. For the mentee, having a formal process will allow him/her to understand how the firm works and also allow the mentee to judge how s/he is doing in the firm.

\section{Summary and Conclusion}

This paper's objective was to provide an overview of the topic of mentoring and to provide some potential solutions to frequent concerns or issues with mentoring. By giving a background on what is mentoring and what are some key traits of successful mentors, mentee and organizations, the paper has provided the reader an insight into what mentoring is and the benefits that can be expected of a mentoring program.

As there is a lot of research covering this topic, it is amazing how misunderstood and underused the mentoring process is. Hopefully, this paper provides a concise set of reason why mentoring is important. One can It is my personal belief based on the research that mentoring is what makes the difference between good performers and stellar performers. In reading some articles, it came through that most successful people have had mentors to assist them through their professional and personal lives. It is the ability to have someone in your comer rooting for you and pulling and pushing you to succeed that has made these people respect mentoring.

People even learn from bad mentoring relationships. Everyone has some pearl of wisdom or thought to impart on another person. Also, bad mentoring relationships make a person appreciate good mentoring relationships and allow the mentee/mentor to understand what is needed for good mentor/mentee.

The last thought about mentoring is summed up nicely in two quotes, "A true mentor does two things: believes in a person and has absolutely no feelings of competition" and "If you want to be a master, study what the masters have done before you. Learn to do what they have done - have the guts to do it-and you will be a master too." (Wickman and Sjodin, 1997)

\section{Appendix A - Mentor Surveys Mentoring Surveys For The Mentor}

1. Would you consider your mentorship successful? What were the two main reasons for your answer?

2. Was this program voluntary? If yes, what was the main reason you volunteered? If no, does your performance effect your compensation or any other benefit in the firm?

3. Were you given any training on how to be a successful mentor? If yes, what kind (generally)? If no, would you have liked to have had formal training?

4. What were your expectations with regards to the mentoring process? Were they fulfilled?

5. Are you evaluated on your performance as a mentor? If yes, is it helpful? If no, would you like to be?

6. What do you took for in a successful mentee?

7. How do you make time for your mentee?

8. Would you continue your relationship with your mentee in the future? Why or why not?

9. If there was one change you could make in the mentor program, what would it be?

\section{Mentoring Surveys For The Mentee}

10. Would you consider your mentorship successful? What were the three main reasons for your answer?

11. What were your expectations with regards to the mentoring process and mentor? Did you communicate that to your mentor?

12. Did you set out your personal objectives or goals with your mentor when you started the process? Or were they developed in the process with the assistance of your mentor?

13. Did your mentor make time for you? How?

14. Were you proactive in your approach with your mentor? Did you or your mentor initiate meetings and discussion topics?

15. Do you think your mentor should be someone who helps you determine your career path and assists you in making career choices or someone who has certain behavior or style you wish to emulate? 
16. Would you consider your mentorship a learning experience or more of a relationship experience? (Learning experience defined as learning new concepts or more about the business; Relationship experience defined as a person in position power who you would keep as a network contact but not as consultant for your personal growth.) Why?

17. Would you continue your relationship with your mentor in the future? Why or why not?

18. If you could make any changes to the program you were in, what would be your number one change?

\section{Appendix B - Bibliography}

1. Abbott, Ida O., The Lawyer's Guide to Mentoring, New York, National Association for Law Placement, Inc. (NALP), 2000.

2. Abbott, Ida O., "Working with a Mentor: 50 Practical Suggestions for Success," New York, National Association for Law Placement, Inc. (NALP), 2000.

3. Alreck, Pamela L. and Settle, Robert B., The Survey Research Handbook, Illinois, Richard D. Irwin, Inc., 1985.

4. Basile, Frank, "Mentoring - a Path Toward Immortality," Indianapolis Business Journal, March 16, 1998, p.16.

5. $\quad$ Bell, Chip R., "The Mentor as Partner," Training \& Development, February 2000, p. 52-57.

6. $\quad$ Borick, Erin A., "Life \& Career Shepherds," Office Pro, March 1998, p. 6-9.

7. Clutterbuck, David \& Megginson, David, Mentoring Executive \& Directors, Oxford, ButterworthHeinemann, 1999.

8. Cohen, Norman H., Mentoring Adult Leamers: A Guide for Educators and Trainers, Florida, Krieger Publishing Company, 1995.

9. Covelski, Mark A. and Dirsmith, Mark W., "The Calculate and the Avowed: Techniques of Discipline and Struggles Over Identity in Big Six Public Accounting Firms," Administrative Science Quarterly, June 1998, p. 293-328.

10. Dansky, Kathryn H., "The Effect of Group Mentoring on Career Outcomes," Group \& Organization Management March 1996, p. 5-22.

11. Duff, Carolyn S., Learning From Other Women, New York, AMACOM, 1999.

12. Edwards, Jack E., Thomas, Marie D., Roenfeld, Paul and Booth-Kewley, Stephanie, How to Conduct Organizational Surveys, California, SAGE Publications, 1997.

13. Feldman, Daniel C., "Toxic Mentors or Toxic Protdg6s? A Critical Re-examination of Dysfunctional Mentoring," Human Resource Management Review, fall 1999, p. 247-279.

14. Goodale, Mark, "Mentoring the Next Generation," Civil Engineering, September 2001, p. 74-76.

15. Gregg, Cecil, "Someone to Look Up To," Journal of Accountancy, November 1999, p. 89-92.

16. Hindo, Brain, "You Paid for Grads' Skill. Now Use Them," Business Week, October 15, 2001, p. 108.

17. Higgins, Monica C., "Reconceptualizing Mentoring at Work: A Developmental Network Perspective," People Management, April 2001, p. 264-289.

18. Hill, Susan Kogier and Bahniuk, Margaret H., "Promoting Career Success Through Mentoring," Review of Business, spring 1998, p. 4-7.

19. *Jeruchim, Joan and Shapiro, Pat, Women, Mentors and Success, Jipson, Janice and Paley, Nicholas, "Because No One Gets There Alone: Collaboration as Co- mentoring," Theory Into Practice, Winter 2000, p. 36-43.

20. Kaplan, Steven E., Annemarie, K. and Walo, Judith C., "An Examination of Perceived Barriers to Mentoring in Public Accounting," Behavioral Research in Accounting, 2001, p. 195-221.

21. Lee, Felissa K., Dougherty, Thomas W., and Turban, Daniel B., "The Role of Personality and Work Values in Mentoring Programs," Review of Business, Spring/Summer 2000, p. 33-37.

22. McDougall, Marilyn and Beattie, Rona, "Peer into the Future," People Management, April 30, 1998, p. 56.

23. McShulskis, Elaine, "Don't Cut Mentoring Programs During Times of Change," HR Magazine, September 1997, p.23-25.

24. Messmer, Max, " Mentoring: Building Your Company's Intellectual Capital," HR Focus, September 1998, p. S11- 13. 
25. Minter, Robert L. and Thomas, Edward G., "Employee Development Through Coaching, Mentoring and Counseling: A Multidimensional Approach," Review of Business, Spring/Summer 2000, p. 43-47.

26. Murray, Margo, Beyond the Myths and Magic of Mentoring, San Francisco, Jossey-Bass, 2001.

27. Murrell, Audrey J., Crosby, Faye J., and Ely, Robin J., Mentoring Dilemmas: Developmental Relationships within Multi-cultural Organizations. New Jersey, Lawrence Erlbaum Associates, Publishers, 1999.

28. Nemanick Jr., Richard C., "Comparing Formal and Informal Mentors: Does Type Make a Difference?" Academy of Management Executive, August 2000, p. 136-139.

29. Parker, Victoria A. and Kram Kathy E., "Women Mentoring Women: Creating Conditions for Connection," Business Horizons, March/April 1993, p. 42-52.

30. Peddy, Dr. Shirley. The Art of Mentoring: Lead, Follow and Get Out of the Way, Texas, Bullion- Books, 1998.

31. Philips-Jones, Linda, Mentors \& Protégés, New York, Arbor House, 1982

32. Raggins, Belle Rose, "Diversified Mentoring Relationships in Organizations: A Power Perspective," Academy of Management Review, April 1997, p. 482-521.

33. Schweitzer, Carole and Dolan, Thomas C., "Mentoring Measures," Association Management, August 2001, p. 38-49.

34. SCORE, "Mentors SCORE in Cyberspace," Indianapolis Business Journal, January 25, 1999, p. 39.

35. $\quad$ Seligman, Dan, "Down with Dyading," Forbes, November 2, 1998, p. 109-1 11.

36. Shea, Gordon F., Mentoring: A Practical Guide, California, Crisp Publications, Inc., 1992.

37. Stokes Jr., Stewart L., "Networking With a Human Face," Information Systems Management, summer 1994, p. 34-40.

38. Wenner, Gretchen, "MBA Roundtable Will Offer Regular Counsel To Local Businesses," Business Journal Serving Fresno \& The Central San Joaquin Valley, August 20, 2001, p. 3

39. Wickman, Floyd and Sjodin, Terri, Mentoring: The Most Obvious Yet Overlooked Key to Achieving More in Life than You Dreamed Possible, Chicago, Irwin Professional Publishing, 1997.

40. Young, Angela M., "The Exchange Relationship Between Mentors And Protégés: The Development of a Framework," Human Resource Management Review, Summer 2000, p. 177- 210.

41. Young, Angela M. and Perrewe, Pamela L., "What Did You Expect? An Examination of Career- Related Support and Social Support Among Mentors and Protégés," Journal of Management, 2000, Vo. 26 Issue 4, p. 611-632.

42. Zachary, Lois J., The Mentor's Guide, California, Jossey-Bass Inc., 2000 Zemke, Ron and Anderson, Kristin, Coaching: Knock Your Socks Off Service, New York, AMACOM, 1997.

43. Zey, Michael G., The Mentor Connection,-Illinois, Dow Jones-Irwin, 1984 "Mentoring \& Coaching Help Employees Grow," HR Focus, September 2001, p. 1-6. 